EfFects of Nitroge Mustard on the Permeability of THE

Blood-Aqueoús Humour Barrier tó Evans Blue 717

\title{
THE EFFECT'S OF NITROGEN MUSTARD ON THE PERMEABILITY OF THE BLOOD-AQUEOUS HUMOUR BARRIER TO EVANS BLUE \\ An instance of the influence of a lesion in one eye on the susceptibility of the other*
}

BY

\section{Hugh Davson and J. P. Quilliam}

PORTON AND LONDON

THE chemical warfare agent, "nitrogen mustard" or methyl bis ( $\beta$-chloroethyl) amine, has come to the notice of the clinician lately on account of its beneficial effect upon Hodgkin's disease, the leucaemias and some neoplasms (Gilman and Philips, 1946). It is also of interest to those studying the problems associated with the changes in the permeability in the blood-aqueous humour barrier since exposure of the eye to nitrogen mustard either in the liquid or vapour form results in a well marked iridocyclitic type of lesion which, in severe cases, may be associated with iris haemorrhages. Similar effects are obtained by dropping a one per cent. aqueous solution into the eye.

The membranes separating the blood from the aqueous humour show a high degree of selectivity; thus the aqueous humour is almost completely protein-free; sucrose, injected into the blood, appears in the aqueous humour only very slowly, whilst the trisaccharide, raffinose, does not appear in the aqueous humour at all (Weld, Feindel and Davson, 1942). Similarly, a large number of dyes, when injected into the blood stream, do not appear in the aqueous humour. "Halpert, German and Hopper, 1933, Amer. Jl. Physiol., Vol. CIII, p. 351). It was considered possible that the damage in the uveal tract caused by nitrogen mustard would manifest itself in the form of an increased permeability of the membranes separating the aqueous humour from the blood stream. If this were indeed the case, then it might be expected that a dye which, when injected into the blood of the normal animal, failed to appear in the aqueous humour, would appear in the aqueous humour of an animal whose eyes had been exposed to this chemical agent. Preliminary experiments showed this to be true; thus chlorazole fast pink, when injected into the blood of the normal rabbit, failed to appear in the aqueous humour; however, after exposure of the animal to nitrogen mustard vapour, the aqueous humour was found to be pink, indicating a change in the selective power of the membranes. The dye finally chosen for these experiments was

\footnotetext{
* From the Chemical Defence Experimental Station, Porton, and the Depart-
} ments of Physiology, University College and King's College, London. 
Evans blue 1024 which has the advantages of being eliminated very slowly indeed from the blood stream, and of giving an intense blue colour at low dilutions.

The work to be described here was undertaken to find out whether the rate of penetration of Evans blue into the eye could be used as an index to the severity of a lesion caused by nitrogen mustard, and to this end the effects of three different preparations of the substance, known to have different toxicities, were compared. The results showed that this was indeed possible; moreover an extremely interesting dependence of the severity of the lesion in one eye on the condition of the other eye became manifest and for this reason that part of the work bearing on this point is being published.

\section{Experimental}

Aqueous solutions of nitrogen mustard were used; on dissolution in water the reagent undergoes a series of changes with time, its activity rapidly diminishing and then rising to a constant value. Thus there were three solutions which could be used, namely nitrogen mustard dissolved in ice-cold water and immediately applied to the eye; the same solution kept for 10 minutes at room temperature, in which case the effectivity would be expected to be minimal ; and finally the same solution kept for five hours at room temperature. Toxicity studies had indicated that the order of effectiveness would be :-

A Ice-cold
B

5 hours
C

10-minutes

Rabbits were injected with $1 \mathrm{ml}$. of a 1 per cent. solution of Evans blue 1024 in isotonic saline per $5 \mathrm{lb}$. body weight. $60 \mathrm{mg}$. of the appropriate solution were instilled into the two eyes. Two hours after the instillation, the aqueous humours were removed from both eyes and the concentrations of Evans blue determined colorimetrically. The severity of the lesion was assessed in terms of the dye concentration in accordance with a somewhat arbitrary scale, the maximal possible dye concentration (namely that in the blood) being given the value 100 , and lower concentrations values in proportion. If we wish to compare the lesions produced by the two weaker solutions $B$ and $C$, we may proceed in two ways :-

(a) A standard lesion may be produced in one eye of all animals with solution $\mathrm{A}$; in one group the other eye would have solution $\mathrm{B}$ instilled into it, and in the other group the other eye would have solution C. The ratio: Lesion A/Lesion B could be compared with the ratio : Lesion $\mathrm{A} /$ Lesion $\mathrm{C}$.

(b) Alternatively, in a group of rabbits, solution B could be 
Effects of Nitrogen: Mustard on the Permeability of the Blood-Aqueous Humour Barrier to Evans Blue 719

instilled into one eye and solution $\mathrm{C}$ into the other, and the lesions directly compared.

If the two eyes of an animal can be treated as independent, we may expect to obtain the same results with both procedures.

\section{Results}

When procedure $(a)$ was used solutions $\mathrm{B}$ and $\mathrm{C}$ produced lesions of intensities of 17 and of 11 respectively (Table 1), solution $B$ being the stronger as toxicity studies indicated. When procedure $(b)$ was adopted, solutions $B$ and $C$ being instilled into the two eyes of the same animal, the lesions were (Table 2) 12 for solution $B$ and $1 \cdot 6$ for solution $C$, i.e., solution $B$ was certainly stronger in effect than

\section{TABLE I}

The lesions produced by three preparations of nitrogen mustard (Solutions A, B and C). In all animals, solution $A$ was instilled into the left eye. The intensity of the Evans blue in the blood was taken as 100 and the values in the aqueous humours recorded below were in proportion and were estimated colorimetrically.

\begin{tabular}{|c|c|c|c|}
\hline \multirow{2}{*}{ No. of Rabbits } & \multicolumn{3}{|c|}{ Average Value of Lesion produced } \\
\hline & L. Eye & R Eye & $r=L$. Eye/R. Eye \\
\hline 18 & $\begin{array}{l}\text { (Solution A) } \\
35\end{array}$ & $\begin{array}{c}\text { (Solution B) } \\
17\end{array}$ & $2 \cdot 3$ \\
\hline 22 & $\begin{array}{l}\text { (Solution A) } \\
36\end{array}$ & $\begin{array}{c}\text { (Solution C) } \\
11\end{array}$ & $3 \cdot 6$ \\
\hline
\end{tabular}

TABLE II

The lesions produced by the two weaker preparations of nitrogen mustard (Solutions B and $C$ ). In all animals solution $B$ was instilled into the left eye, solution $\mathrm{C}$ into the right.

Method of estimation as referred to in Table 1.

\begin{tabular}{c|c|c|c}
\hline \multirow{2}{*}{ No. of Rabbits } & \multicolumn{3}{|c}{ Lesion } \\
\cline { 2 - 3 } & L. Eye & R. Eye & r=L. Eye/R. Eye \\
\hline \multirow{2}{*}{18} & $\begin{array}{c}\text { (Solution B) } \\
12\end{array}$ & $\begin{array}{c}\text { (Solution C) } \\
1 \% 6\end{array}$ & 9 \\
\hline
\end{tabular}


solution $\mathrm{C}$, as indicated in the first series; but with this procedure it appears to be some nine times as effective whereas with procedure (a) it appears to be only about one and a half times as effective. The reason for this difference, as the Tables show, is that the weakest preparation, solution $C$, produces a very small lesion $\left(1^{\circ} 6\right)$ when the other eye has solution $\mathrm{B}$ in it, whereas it produces a considerably larger one (11) when solution A is in the other eye. Solution B produces a larger lesion when solution $A$ is in the other eye but the effect is not so great, so that the effect of passing from the one procedure to the other is to modify the ratio: Lesion $B /$ Lesion $C$ very considerably.

Now the solution $A$ is the most effective in causing lesions (it causes a lesion of 36 when solution $C$ causes 11 , and 35 when solution $B$ causes 17) and the results can best be explained if the instillation of the powerful solution $A$ tends to produce an incipient lesion in the other eye; the effect of the weakest solution (C) will therefore be stronger when solution $A$ is in the other eye than when solution $B$ has been instilled.

\section{Discussion}

The two eyes- of a rabbit are not necessarily to be viewed as mutually independent organs but rather each as being individually susceptible to changes going on in the other. The reciprocal action is probably reflex in origin, since it is hard to believe that the small quantities of toxic material actually absorbed into the blood from the conjunctival sac could be sufficient to have any general effects by way of the blood stream. The effective barrier which separates the anterior chamber from the blood in the anterior part of the iris is possibly only that due to the endothelial lining of the capillaries, since the endothelium of the iris contains lacunae of sufficient size to prevent it from acting as an intact membrane. It is well known that the permeability of the capillary endothelium to proteins, and therefore to Evans blue, is largely determined by the physiological state of the capillaries; if they are dilated their permeability is high, if contracted, it is low. If the lesion produced by a high concentration of nitrogen mustard in one eye causes a reflex dilatation of the vessels in the iris of the other, then the phenomena described here are explicable on the basis of reflex action. In confirmation of this viewpoint it has been noted that by instilling nitrogen mustard into the left eyes of a group of animals a ciliary injection was observed in the untreated right eyes; only on one occasion, however, was it possible to demonstrate that injected Evans blue appeared in the. contra-lateral eye. We may therefore conclude that a severe lesion in one eye potentiates the action of a mild nitrogen-mustard agent in the other by reflex action; in the present case the effects of this 
potentiation are greater with the milder solution $\mathrm{C}$ than with the stronger solution $\mathrm{B}$.

We are indebted to Sir Stewart Duke-Elder for advice and to the Chief Scientist, the Ministry of Supply, for permission to publish this paper.

\section{REFERENCES}

Gilman, A. and Philips, F. S. (1946), Science, Vol. CIII, p. 409.

Halpert, B., German, W. J. and Hopper, E. G. (1933), Amer. J. Physiol. Vol. CIII, p. 351.

Weld, C. B., Feindel, W. H. and Davson, H. (1942), Amer. J. Physiol. Vol. CXXXVII, p. 421.

\section{PERIPHERAL AND CENTRAL DISTURBANCES OF THE VISUAL FIELDS. AN ASPECT OF DI-OPHTHALMOLOGY*}

BY

\section{N. A. Stutterheim \\ JOHANNESBERG}

THE cause of eyestrain, concomitant squint, and amblyopia used to be unknown, the diagnosis incorrect, the therapy inadequate and therefore the prognosis dubious. It was not until convergence had been recognized as the kinetic principle of bi-foveal vision $^{1,2,3,4}$ that the dynamic factor of human binocular vision was established. From then on the diagnosis, prognosis as well as therapy of these disorders could be shaped on rational lines within the precincts of physiology where they belong. These disorders concern the physiology of the bi-foveal eye, the di-ophthalmos, of which the bi-fovea is the highest achievement.

If each of the three following cases were assessed by the usual standards of ophthalmology, they would have a very sombre prognosis. In these cases, there was no workable diagnosis and therefore no therapy, until they could be recognized as disorders of the di-ophthalmos.

\section{Case I}

L., a sctioolboy, aged 17 years, was referred to me by his uncle, a specialist-physician, on July 7, 1946 (abbreviated letter) :-

I- have referred L. du P. to you. His parents are very crincerned as to his condition, and would like to know what the future holds.

\footnotetext{
* Received for publication, March 25, 1947.
} 